\title{
A SURVEY OF SMART ELECTRICAL BOARDS IN UBIQUITOUS SENSOR NETWORKS FOR GEOMATICS APPLICATIONS
}

\author{
S.M.R. Moosavi ${ }^{\text {a, }}$, A. Sadeghi-Niaraki ${ }^{\text {b }}$ \\ ${ }^{a}$ Dept. of Geomatic Engineering, Islamic Azad University, Larestan, Iran. - hseyyed@ gmail.com \\ ${ }^{\mathrm{b}}$ GIS Dept., Geoinformation Technology Center of Excellence, Faculty of Geodesy\&Geomatics Eng, K.N.Toosi Univ. of Tech., \\ Tehran, Iran. - a.sadeghi@kntu.ac.ir
}

KEY WORDS: Smart boards, ubiquitous sensor networks, Arduino, Raspberry Pi, physical computing, ubiquitous GIS

\begin{abstract}
:
Nowadays more advanced sensor networks in various fields are developed. There are lots of online sensors spreading around the world. Sensor networks have been used in Geospatial Information Systems (GIS) since sensor networks have expanded. Health monitoring, environmental monitoring, traffic monitoring, etc, are the examples of its applications in Geomatics. Sensor network is an infrastructure comprised of sensing (measuring), computing, and communication elements that gives an administrator the ability to instrument, observe, and react to events and phenomena in a specified environment. This paper describes about development boards which can be used in sensor networks and their applications in Geomatics and their role in wireless sensor networks and also a comparison between various types of boards. Boards that are discussed in this paper are Arduino, Raspberry Pi, Beagle board, Cubieboard. The Boards because of their great potential are also known as single board computers. This paper is organized in four phases: First, Reviewing on ubiquitous computing and sensor networks. Second, introducing of some electrical boards. Then, defining some criterions for comparison. Finally, comparing the Ubiquitous boards.
\end{abstract}

\section{INTRODUCTION}

Nowadays more advanced sensor networks in various fields are developed. There are lots of online sensors spreading around the world. Sensor networks have been used in Geospatial Information Systems (GIS) since sensor networks have expanded. Health monitoring (Kemis et al., 2012), environmental monitoring (Son et al., 2006) (Choi et al., 2015), traffic monitoring (Costanzo, 2013), etc, are the examples of its applications in Geomatics. A sensor is a device that receives a stimulus and responds with an electrical signal (Fraden, 2010). Sensor is a transducer which purpose is to sense some characteristics of its environs. It receives signal or energy from physical environment to make it readable and provide corresponding output information. The readable output of electrical sensors is the variation of output voltage which it has converted to an understandable data to human. Sensors are connected to the Internet or an internal network. They send their location and the recorded or online environmental data. Sensor can be controlled remotely and human interaction with the physical environment can be provided. Sensors' Applications include manufacturing and machinery, airplanes and aerospace, cars, medicine and robotics.it is also included in our day-to-day life.

\section{UBIQUITOUS COMPUTING}

The phrase "Ubiquitous Computing" has invented by Mark Weiser around 1988, during his tenure as Chief Technologist of the Xerox Palo Alto Research Center (PARC). Weiser wrote some of the earliest papers both alone and with PARC Director and Chief Scientist John Seely Brown on the subject, largely defining it and sketching out its major concerns (Weiser, 1996).
Ubiquitous computing, or ubicomp, is the term given to the third era of modern computing. The first era was defined by the mainframe computer. Second, is the era of the PC, a personal computer used by one person and dedicated to them. The third era, ubiquitous computing, representative of present time, is characterized by explosion of small networked portable computer products in the form of smart phones, PDAs, and embedded computers built into many of the devices, Figure 1 (Krumm, 2010). Ubiquitous computing is the method of enhancing computer used by making many computers available throughout the physical environment, but making them effectively invisible to the user. One of the positive effects from ubiquitous computing is people who do not have skills use the computer and people with the physical lack (the defect) could continue to use the computer for all the needs. Ubiquitous technology means the ability to access to any services and gathering information in any location such as country, city, workplace and even home, any time, by anyone, by any device and in any network (LAN, Wireless etc.). In ubiquitous perspective every element of real world can communicate together.

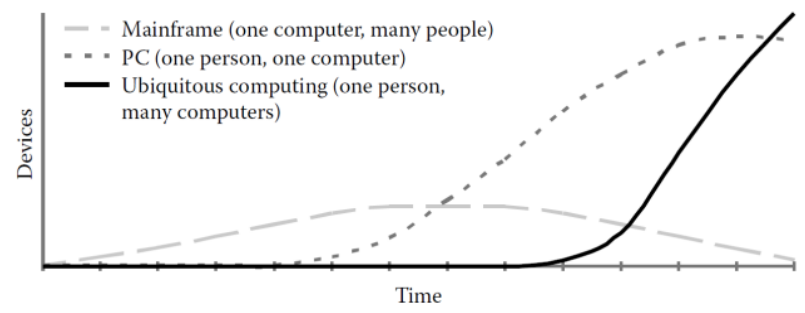

Figure 1. Graph conceptually portraying three eras of modern computing.

\footnotetext{
* Corresponding author
} 


\section{SENSOR NETWORK}

Sensor network is an infrastructure comprised of sensing (measuring), computing, and communication elements that gives an administrator the ability to instrument, observe, and react to events and phenomena in a specified environment. The administrator typically is a civil, governmental, commercial, or industrial entity. The environment can be the physical world, a biological system, or an information technology (IT) framework (Sohraby et al., 2007). The technology for sensing and control includes electric and magnetic field sensors; radio-wave frequency sensors; optical-, electro-optic, and infrared sensors; radars; lasers; location/navigation sensors; seismic and pressure wave sensors; environmental parameter sensors (e.g., wind, humidity, heat). Today's sensors can be described as "smart" inexpensive devices equipped with multiple on-board sensing elements; they are low-cost, low-power untethered multifunctional nodes that are logically homed to a central sink node.

\section{USN, U-GIS}

In order to have Ubiquitous GIS (UBGIS), an integration of Ubiquitous computing and traditional GIS is necessary. By using UBGIS, any user or any system through any communication device can access to geographic information and applications at any time and any place. The dynamic context of the user is playing the major role of UBGI. For achieving the dynamic context in UBGIS, ubiquitous computing concepts should employ Ubiquitous Sensor Networks (USNs) to collect any data on any environmental parameter. Dynamic context is defined as dynamic location and the identity of any object, people and parameter in environment. Ubiquitous sensor networks (USN) consist multiple nodes, each node can independently communicate with a server or using wireless technology that connects nodes together and they all connect to a server through a router node. In addition of sensor, there are hardwares such as electronic board, network modules in order to process data and communicate to the server. Electronic boards have the task of pre-processing of the sensor's output. By developing them, they will have the ability to connect to a network. Boards with the programming ability can analyse the sensor's output and affects its surroundings by controlling lights, motors, and other actuators. Actuators are things like lights and LEDs, speakers, motors, and displays.

\section{PHYSICAL COMPUTING}

Physical computing is interactive physical systems which can sense and respond to the analog world. It's a creative framework for understanding human beings' relationship to the digital world, Figure 2. Interaction is "A cyclic process in which two actors alternately listen, think, and speak" (Crawford, 2003). "Interactive" is a fuzzy term, and often misused for all kinds of purposes and most physical computing projects can be broken down into these same three stages: listening, thinking, and speaking - or, in computer terms: input, processing, and output (O'Sullican and Igoe, 2004).

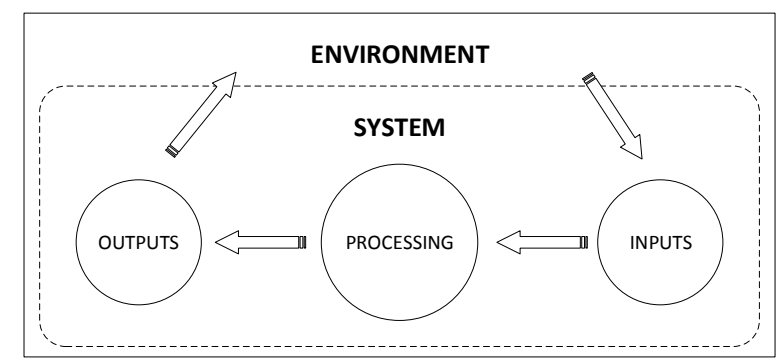

Figure 2. Physical Computing

\section{ELECTRONIC BOARDS}

For pre-processing sensors' output and communication with the server or a router node, an electronic circuit is necessary. In the past for any type of sensor and application, a circuit should be designed. But by recent development in electronic boards, a lot of boards have seen that can connect to variety of sensors and other equipment such as wireless connectivity modules or GSM modules. These boards have called "Single Board Microcontroller". Single board microcontroller is a microcontroller that built onto the single printed circuit. This board contain all necessary element to do a task such as: microprocessor, RAM, I/O circuits, etc. The intention is that the board is immediately useful to an application developer, without spending much time and effort in developing the controller hardware. Some of single board microcontrollers because of their great potential, computing and connectivity options also known as single board computers. There are types of boards some of them kind of open source computing hardwares that follow the open community to let the users to redesign and develop them. This paper discuss about some boards such as: Arduino, Raspberry Pi, Beagle board and Cubieboard.

\subsection{Arduino}

Arduino is a tool for making computers that can sense and control more of the physical world than the desktop computer. It's an open-source physical computing platform based on a simple microcontroller board, and a development environment for writing software for the board. The project is based on a family of microcontroller board designs manufactured primarily by SmartProjects in Italy and also have cloned by several other vendors. An Arduino board consists an 8, 16bit or 32bit Atmel AVR microcontroller with other components to facilitate the incorporation with other circuits. One of the advantages of Arduino is its standard connectors that let user to connect board to variety of modules known as shields. The communication of some shields with Arduino board can be done by directly over various pins, there are also some shield that individually are addressable via serial bus. So many shields can be used in parallel. Early Arduino boards used to be programmed via RS232 ports, however current boards can be programmed via USB and also some unofficial models programmed over a Bluetooth connection. The Arduino board is where the code has written and executed. The board can only control and respond to electricity, so specific components are attached to it to enable it to interact with the real world. These components can be sensors, which convert some aspect of the physical world to electricity so that the board can sense it, or actuators, which get electricity from the board and convert it into something that changes the world. Examples of sensors include switches, accelerometers, and ultrasound distance sensors. Arduino board is real-time which means no operating system installed on them, this capability is useful for fast responses (Margolis, 2012). 


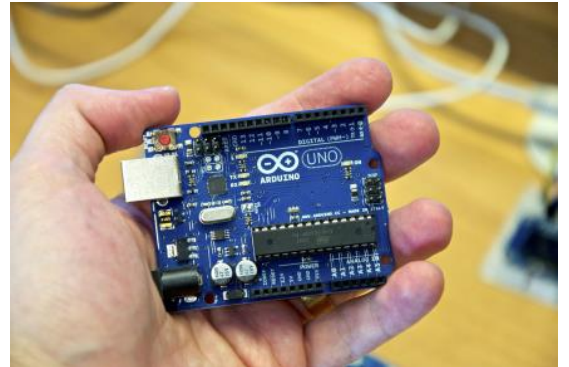

Figure 3. Arduino Uno

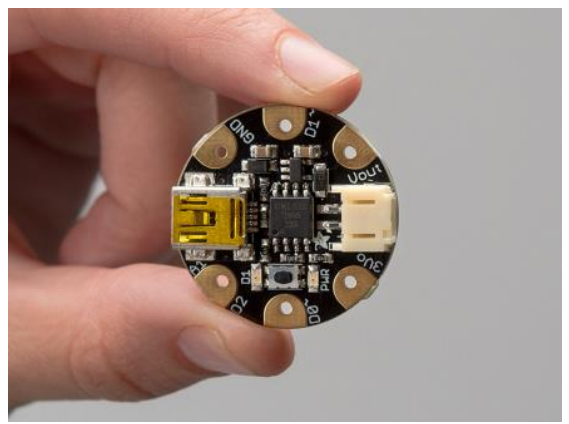

Figure 4. Arduino Gemma (wearable)

\subsection{Raspberry Pi}

The Raspberry Pi is a credit-card-sized computer (Single-Board Computer) created by the non-profit Raspberry Pi Foundation in the UK. It all started when a chap named Eben Upton (now an employee at Broadcom) got together with his colleagues at the University of Cambridge's computer laboratory, to discuss how they could bring back the kind of simple programming and experimentation that was widespread among kids in the 1980s on home computers such as the BBC Micro, ZX Spectrum, and Commodore 64 (Sjogelid, 2013). The Raspberry Pi is built off the back of the Broadcom BCM2835 and BCM2836 SoCs. These SoCs are multimedia application processors geared towards mobile and embedded devices which includes $A R M$ processor, GPU, $512 \mathrm{Mb}$ to $1 \mathrm{~GB}$ RAM, and MicroSD socket for boot media and persistent storage (Dennis, 2013). Operating systems like Linux and Windows 10 can be installed on Raspberry Pi. Raspberry Pi main programming language is python and also supports: Java, C, C++ and Ruby.

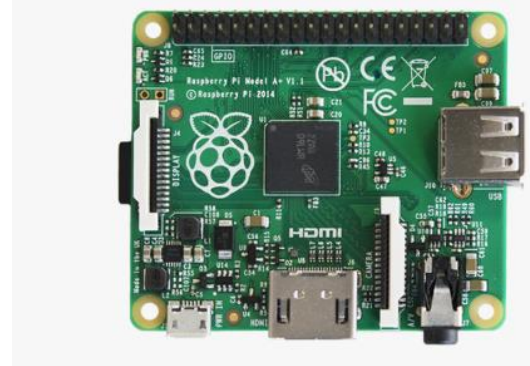

Figure 5. Raspberry Pi A+

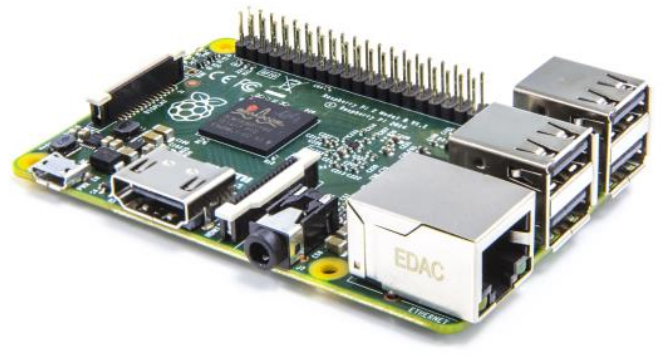

Figure 6. Raspberry Pi 2 B

\subsection{BeagleBoard}

The BeagleBoard is an open-source single-board computer produced by Texas Instruments in association with some other companies. The BeagleBoard also designed with open source software. The board base on ARM architecture and it's included GPU to provide 2D and 3D rendering that supports OpenGL. Some models have both video outs which provided through SVideo and HDMI connections. A single SD card also included that supports USB On-The-Go.

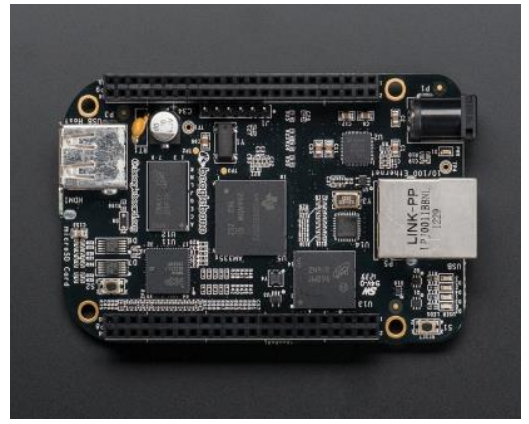

Figure 7. BeagleBone Black

\subsection{CubieBoard}

CubieBoard is a Single-Board-Computer which made in china. It can run Android 4 ICS, Ubuntu 12.04 desktop, Fedora 19 ARM Remix desktop, Archlinux ARM, a basic Debian server via the Cubian distribution, or OpenBSD.

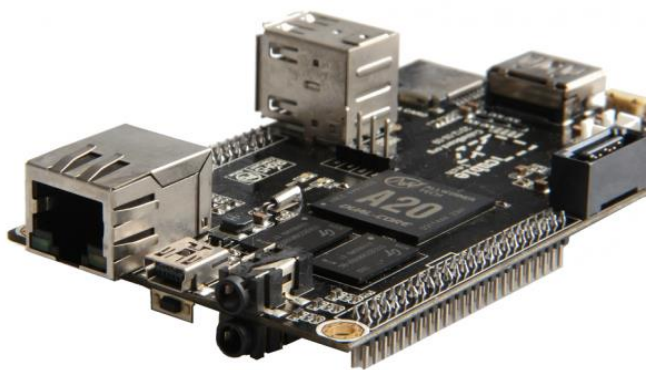

Figure 8. CubieBoard 2 


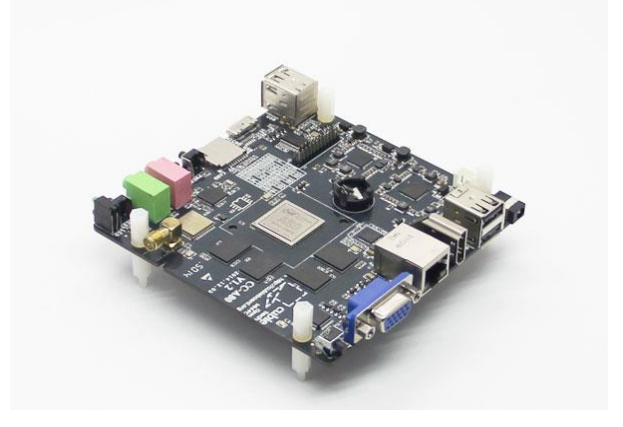

Figure 9. CubieBoard 4 (CC A80)

\section{CRITERIONS}

To choose an appropriate board some criterions are necessary such as price, power consumption, expandability and compatibility, ease of use and development, information resource availability for beginners. For better understanding of power consumption related to Table. 1: Voltage is measured in units of volts (V). With the symbol $\mathrm{V}$, it is the measure of potential in a circuit. The oft used analogy is water - voltage then becomes the height from which the water is flowing or falling. Greater height, more potential energy from the water flow, similarly greater voltage, more potential energy. Current is measured in units of amperes (A), usually abbreviated to amps, and is the rate of flow of electric charge past a point. The symbol used for current is I. To continue the water analogy, current might be considered the width/depth of the water flow. Power is the amount of energy in a system, and is measured in units of watts (W). With the symbol $\mathrm{P}$, in quantitative terms for an electrical circuit, it is equal to current $\times$ voltage. Hence, $\mathrm{P}=\mathrm{I} \times \mathrm{V}$. To round out the water analogy, there is a lot more power in Niagara Falls than the downpipe on the side of a house (Oxer and Blemings, 2010). Price is an important criterion because ubiquitous networks are implemented in a large scale. Another important criterion is power consumption, need to know the places that sensor should be installed. There is lack of power in some places, so if power consumption of hardware were low, the boards can be work by small solar cells which solar cells charge batteries in day to save energy for board in night. More power consumption needs bigger solar cells and bigger solar cells get more expensive. Expandability in electronic boards means the board has the ability to support more add-on shields and modules (e.g. GSM shield (Costanzo, 2013), Display controllers, Motor controllers, Wi-Fi module such as Xbee (Harikrishnan, 2015)) boards can do more tasks with shields and modules and compatibility with them. Generally open source boards are easy to use and develop and in case of open source, the hardware and software can be modified by project goal.

Table 1. Board Comparison

\begin{tabular}{|c|c|c|c|c|c|c|c|c|c|}
\hline \multirow{2}{*}{ Brand } & \multirow{2}{*}{ Model } & \multirow{2}{*}{ Size $(\mathrm{mm})$} & \multirow{2}{*}{$\begin{array}{c}\text { Cost } \\
\text { (US\$) }\end{array}$} & \multicolumn{2}{|r|}{$\mathrm{CPU}$} & \multirow{2}{*}{ Flash Memory } & \multirow{2}{*}{$\begin{array}{c}\text { Operating } \\
\text { Voltage }\end{array}$} & \multirow{2}{*}{$\begin{array}{c}\text { Power } \\
\text { Consumption }\end{array}$} & \multirow{2}{*}{ Operating System } \\
\hline & & & & Core & Speed (MHz) & & & & \\
\hline \multirow{5}{*}{ Arduino } & Uno & $68.6 \times 53.4$ & 24.95 & 1 & 16 & $32 \mathrm{~KB}$ & $5 \mathrm{~V}$ & $<0.5 \mathrm{~W}$ & - \\
\hline & Pro & $\begin{array}{c}52.07 \times 53.3 \\
4 \\
\end{array}$ & 14.95 & 1 & 8 & $16 \mathrm{~KB}$ & $3.3 \mathrm{~V}$ & $<0.5 \mathrm{~W}$ & - \\
\hline & Gemma & Q27.98 Dia & 9.95 & 1 & 8 & $8 \mathrm{~KB}$ & $3.3 \mathrm{~V}$ & $<0.5 \mathrm{~W}$ & - \\
\hline & LilyPad & Q 51 Dia & 19.95 & 1 & 8 & $16 \mathrm{~KB}$ & $2.7 \mathrm{~V}$ & $<0.5 \mathrm{~W}$ & - \\
\hline & Nano & $45 \times 18$ & 4.25 & 1 & 16 & $16 \mathrm{~KB}$ & $5 \mathrm{~V}$ & $<1 \mathrm{~W}$ & - \\
\hline \multirow{3}{*}{ Raspberry Pi } & Pi $1 \mathrm{~A}+$ & $65 \times 56.5$ & 25 & 1 & 700 & MicroSD & $5 \mathrm{~V}$ & $1 \mathrm{~W}$ & Linux \\
\hline & Pi $1 \mathrm{~B}+$ & $86 \times 56$ & 39.95 & 1 & 700 & MicroSD & $5 \mathrm{~V}$ & $3 \mathrm{~W}$ & Linux \\
\hline & Pi 2 B & $86 \times 56$ & 41.95 & 4 & 700 & MicroSD & $5 \mathrm{~V}$ & $4 \mathrm{~W}$ & Linux/Windows 10 \\
\hline BeagleBoard & $\begin{array}{c}\text { Beaglebone } \\
\text { Black }\end{array}$ & $86.40 \times 53.3$ & 50 & 1 & 1000 & $4 \mathrm{~GB}$ & $5 \mathrm{~V}$ & $2.3 \mathrm{~W}$ & Linux/Android/WinCE \\
\hline \multirow{2}{*}{ Cubie Board } & Ver. 2 & $100 \times 60$ & 70 & 2 & 1000 & $4 \mathrm{~GB}$ & $5 \mathrm{~V}$ & $10-15 \mathrm{~W}$ & Linux/Android \\
\hline & CC A80 & $111 \times 111$ & 135 & 8 & 1300 & $8 \mathrm{~GB}$ & $5 \mathrm{~V}$ & $10-15 \mathrm{~W}$ & Linux/Android \\
\hline
\end{tabular}

\section{CONCLUSION}

Based on comparison table boards with lowest prices are Arduino, Arduino boards also use low energy consumption, when the device energy consumption is low there is room to add more sensor and add-ons. Also lack of operating system on Arduino boards is a benefit for real-time computing and responses. In case of small volume of data that received from sensors, boards do not need much memory and CPU speed. BeagleBoard and Cubie boards have great performances but due to high price and high power consumption are not good choices for Ubiquitous sensor networks, but can be used as a server. Raspberry Pi boards because they host an operating system are good for large computing and data logging and in case of factory ready Ethernet module, better communication to network is available. Raspberry Pi also can connect to multiple Arduino boards (with Wi-Fi or other methods) and receive and analyse the data. In case of existence of good information resources, ease of software and hardware development, Arduino and Raspberry Pi as smart boards are considered as a good choice to build Ubiquitous sensor networks (Ferdoush and Li, 2014). Most researches in ubiquitous GIS have not been tested in the real world (especially in Iran), due to the lack of electrical knowledge of Geomatic students. These boards called DIY (DoIt-Yourself) boards, the operation is simple and lots of resources are available.

\section{REFERENCES}

Choi, Y., Hong, S., Joe, I., 2015. A Fire Evacuation Guidance System Based on Ubiquitous Sensor Networks, in: Advanced Multimedia and Ubiquitous Engineering. Springer, pp. 217-222.

Costanzo, A., 2013. An arduino based system provided with GPS/GPRS shield for real time monitoring of traffic flows. 2013 7th Int. Conf. Appl. Inf. Commun. Technol. pp. $1-5$. 
Crawford, C., 2003. The Art of Interactive Design, No Starch Press. San Francisco, pp. 5.

Dennis, A.K., 2013. Raspberry Pi Home Automation with Arduino. Packt Publishing, Brimingham, pp. 9-11.

Ferdoush, S., Li, X., 2014. Wireless Sensor Network System Design Using Raspberry Pi and Arduino for Environmental Monitoring Applications. Procedia Comput. Sci. 34, pp. 103-110.

Fraden, J., 2010. Handbook of Modern Sensors Physics, Designs, and Applications, Fourth Edition, Springer. New York, pp. 2.

Harikrishnan, R., 2015. An Integrated Xbee Arduino and Differential Evolution Approach for Localization in Wireless Sensor Networks. Procedia Comput. Sci. 48, pp. 447-453.

Kemis, H., Bruce, N., Ping, W., Antonio, T., Gook, L.B., Lee, H.J., 2012. Healthcare monitoring application in ubiquitous sensor network: Design and implementation based on pulse sensor with arduino, pp.34-38.

Krumm, J., 2010. Ubiquitous Computing Fundamentals. Taylor \& Francis, New York, pp. 2-3

Margolis, M., 2012. Arduino Cookbook, O’Reilly. Cambridge. pp. 2.

O'Sullican, D., Igoe, T., 2004. Physical Computing, Thomson. Boston, pp. xx.

Oxer, J., Blemings, H., 2010. Practical Arduino: Cool Projects for Open Source Hardwar. Apress, New York, pp. 2

Sjogelid, S., 2013. Raspberry Pi for Secret Agents. Packt Publishing, Brimingham, pp. 7-8.

Sohraby, K., Minoli, D., Znati, T., 2007. Wireless Sensor Networks: Technology, Protocols, and Applications. John Wiley \& Sons, New Jersey, pp. 1-2.

Son, B., Her, Y., Kim, J., 2006. A design and implementation of forest-fires surveillance system based on wireless sensor networks for South Korea mountains. Int. J. Comput. Sci. Netw. Secur. 6, pp. 124-130.

Weiser, M., 1996. Ubiquitous Computing [WWW Document]. URL http://www.ubiq.com (accessed 4.9.15). 